\title{
Failure in school, family conflicts, and psychosomatic disorders in adolescence*
}

\author{
KLAUS HURRELMANN, UWE ENGEL, BIRGIT HOLLER, AND \\ ELISABETH NORDLOHNE
}

\begin{abstract}
Adolescence is considered to be a transitory phase in the life course. It is hypothesized that failure in school, which carries the risk of an occupational and social "downward mobility" in the future life course in comparison to the family of origin, can function as a social "stressor" which has detrimental effects on the social and emotional climate within the family and manifests itself in symptoms of stress such as psychosomatic disorders. The results are based on a questionnaire survey carried out with a representative sample of 1717 students aged $13-16$ in West Germany. The data support the hypotheses: psychosomatic symptom frequency is reinforced when adolescents experience failure in school and social and emotional conflict in their relationships with parents. Multivariate analysis shows that these effects are interconnected: failure in school has a direct effect on the frequency of psychosomatic disorders, and an indirect effect by influencing social and emotional conflicts in the family. The underlying causes for the tensions between adolescents and their parents are conceived in the social and economic opportunity structures of the society.
\end{abstract}

\section{INTRODUCTION}

\section{Theoretical orientation and hypotheses}

In all industrial societies, adolescence is defined as a period in which decisions are made in important areas of life which affect the social and occupational status of adulthood (Engel, r987; Hurrelmann, r987). This is especially true in the case of formal education. The position which an adolescent assumes within the educational system offers particular options to $\mathrm{him} /$ her in subsequent educational courses and future occupational careers, and at the same time prevents him/her from pursuing other options. On the basis of previous studies, we know that one of the important determining factors in this respect is the social background of the family (Boudon, I974;

Reprint requests to Klaus Hurrelmann, SFB 227, University of Bielefeld, POB 8640, D-4800 Bielefeld, FRG.

- Report on the project "Social Origins of Problem Behavior in Adolescence", as part of the research program of the special research unit 227 "Prevention and Intervention in Childhood and Adolescence", funded by the German Research Association, DFG. This paper has been translated by Adelheid Baker.

$0140-1971 / 88 / 030237+I_{3} \$ 03.00 \%$

(C) 1988 The Association for the Psychiatric Study of Adolescents 


\section{K. HURRELMANN, U. ENGEL, B. HOLLER, AND E. NORDLOHNE}

Persell, I977). The financial resources, the environmental living conditions, and the socialization pattern and cultural lifestyle of the family of origin play a decisive role in determining the success or failure of children in school, the ensuing choice of further educational courses or school types at the secondary level, the organization of the entire school career, and the attainment of school-leaving certificates and diplomas (Collins, 1979; Entwisle and Hayduk, I981; DiMaggio, 1982).

\section{Educational expectations and occupational opportunities}

In the last two centuries, the educational opportunities of adolescents have clearly increased. In the Federal Republic of Germany, for example, the proportion of 7 th-graders in intermediate school (Realschule, the type of school leading to a certificate securing entry into white-collar, business, or skilled-trade occupations) and grammar school (Gymnasium, the school enabling university entrance by offering the Abitur diploma), rose from 26 per cent in 1960 to 56 per cent in 1985 . The chances of attaining the levels set by intermediate school and grammar school have also considerably improved during this period (Bundesminister für Bildung und Wissenschaft, I986, p. $66)$. Thus, the numbers of those entering an advanced secondary school as well as their success rates have increased. It can be said that in the FRG an enormous "educational expansion" has taken place (Hurrelmann, I984a).

A direct consequence of these developments has been a change in the social status of high-quality school-leaving certificates: These are no longer members of an elite, but have become typical for the majority of an age group. A grammar school-leaving certificate, attained by nearly a third of an age group today, no longer guarantees access to top careers of highly qualified occupations as it was the case 20 years ago. The leaving certificate of the intermediate school has become a kind of "standard civil attribute" of every adolescent, a necessary instrument ensuring access to the middle and higher level careers, especially in business and the service sector.

An extended general school education beyond the age of compulsory schooling has become a necessary, but not sufficient condition of entry into attractive courses of vocational training. This process is accelerated by a tightening of the labour market which has made the transition from school to work extremely difficult, at least for the less qualified.

As a result, adolescence in the 1980 s is characterized by an extended school career, which poses specific demands on behaviour in terms of scholarly achievement. Adolescence has become identical with the period of formal schooling and, in view of the fierce competition for favourable starting positions in relation to future careers, constitutes a period of challenge in which young people have to cope with vital, biographically relevant tasks and 
problems. For a majority of adolescents, social integration into the employment sector occurs late in biographical terms or even fails completely. By contrast, integration into the sphere of politico-ethical commitments, friendships and sexual relations, and of cultural and consumer orientations takes place relatively early. Accordingly, adolescents have to develop different profiles of social competences and responsibilities in different societal sectors at different times (Coleman, I980; Hamburg, I980).

\section{The importance of school achievement for the status transition}

We must assume that the process of the upgrading of formal education has led to high educational demands and parental expectations being placed upon adolescents. The children of middle- and upper-class families are forced to develop effective strategies to avoid downward social mobility to maintain careers which are consistent with their parents' social status. Students from lower-class families are forced to develop strategies that counteract increasing competition and assist in achieving the best possible starting positions for the transition to the employment sector. For this reason, all social classes direct their efforts to obtaining the most highly qualified school-leaving certificates. The "optimization of chances" is an integral part of the behavioural strategy of all social classes. As a result, school is the arena in which the social classes compete for the best starting positions in the employment sector (Bourdieu, I984).

The present study approaches the question of whether this specific constellation of conditions has an effect on the social well-being of adolescents. We can expect a high level of insecurity regarding status expectations in those adolescents who, due to poor performance in school or school failure, are threatened by the risk of "downward mobility" and, as a consequence, may be unable to fulfill their parents' aspirations in relation to the school career. Although a certain amount of status insecurity is usual with students in secondary school-due to the transitory character of this phase of life-we must nevertheless expect that a marked increase in status insecurity will lead to "psychosocial costs" that may become manifest in symptoms of psychosocial stress (Hurrelmann, I984b).

Since it is academic achievement above all else which will determine future occupational status, adolescents compare their own position in this phase of the status transition to that of their parents: the possibility of social advancement is as likely as is the threat of social decline. If the danger of downward mobility becomes real, due to school failure or having to repeat a grade or failing the final examinations, then a risk constellation arises for the occurrence of symptoms of psychosocial stress. 
School achievement, family conflicts, and psychosocial disorders

The assumption is that the social and emotional climate present in the family is affected by the risk of downward mobility. The social and emotional climate in the family is an important moderating factor in the process leading to the occurrence of symptoms of stress. Family ties during adolescence are very complex: on the one hand, economic dependence on parents has increased in comparison to the parents' own generation because of the long time spent in school and vocational training. On the other hand, social and emotional relations with parents are no longer as close as they were in the past due to early opportunities for independent decision-making in the peer group and in the areas of leisure and consumption. Adolescents increasingly develop lifestyles of their own. The process of separation from parents takes place in different domains of everyday life and at different periods of time, sometimes leading to strained relationships with parents (Hurrelmann, I987).

A risk constellation for the emergence of symptoms of psychosocial stress can be expected when there is conflict with parents over school performance and educational aspirations. Another risk constellation may arise in case of emotional tensions with parents, for example, when adolescents feel discontented and not fully accepted by their parents with respect to their individual lifestyles. Adolescents' relations to their parents contain a strong emotional element, but at the same time they are also tied up with the parents' role expectations directed to the children's scholastic achievements and prospective status aspirations. This is a potential source of tension.

In this study, we follow the general assumptions of stress research stating that the manifestations of stress can be observed at many levels of the organism, including its psychological and emotional functioning, the nervous system, general physical health, the functioning of various organs as well as the endocrine and the immunological system (Siddique and D'Arcey, I984; Pearlin, 1987). We assume that disorders at one level can lead to disorders at another level and have a reciprocal effect. Taking failure in school-or, more generally, the risk of downward mobility-as a "social stressor", and variants of the social and emotional family climate as "stress mediators", we will concentrate on vegetative and physiological symptoms of psychosomatic disorders as "stress outcomes" or manifestations. We assume that the status insecurity resulting from failure in school is eventually detrimental to health and well-being, particularly in cases where no favourable familial conditions exist that might lessen the impact of failure.

The relations between stressful conditions of life, critical life events, and role strain, on the one hand, and stress outcomes, on the other, have so far been studied mainly with reference to adults. We need to modify existing theoretical concepts and empirical instruments to provide us with methods 

suited to the study of adolescence as a distinctive phase of life. Good examples are, among others, the works of Moriarty and Toussieng (1976), Jessor and Jessor (1977), Hotaling, Atwell and Linsky (1978), Johnson (1986) and the studies assembled by Silbereisen, Eyferth, and Rudinger (1986).

The present study tries to follow in this tradition. It means we can utilize the theoretical and methodological advantages of examining adolescence as a period of life marked by fast-moving, decisive processes of transition leading from one social status to another. Research can concentrate on the analysis of the early development of symptoms and indicators of social stress. The study of the physical, cognitive, emotional and social development in adolescence can thus provide important information on later phases of life (Murphy and Moriarty, 1976; Rutter, 1980; Newcomb, Huba and Bentler, r98r ; Petersen and Craighead, I986).

\section{Hypotheses}

The following empirical analysis is guided by three hypotheses as derived from the previous discussion:

I. The frequency of psychosomatic disorders increases when the risk of downward mobility because of failure in school is obvious. When the educational status of the adolescent is at stake or has actually deteriorated, the risk of subsequent social downward mobility compared to the parents' status is subjectively experienced by him/her, and we can expect psychosomatic reactions relating to this experience.

2. The frequency of psychosomatic disorders increases when there is social conflict in the parental home. We assume that social conflict functions as a mediator precipitating the occurrence of psychosomatic symptoms.

3. The frequency of psychosomatic disorders increases when emotional conflict exists in the relations to parents. We assume that emotional conflict functions as a mediator precipitating the occurrence of psychosomatic symptoms.

\section{METHOD}

\section{Sample}

The results presented below are based on a questionnaire survey involving ${ }_{17} 7$ students aged ${ }_{13}-16$ conducted in the winter of 1986 . We collected data from 7 th- and 9 th-graders from all four school types providing the first stage of secondary education in the West German federal state of North Rhine Westphalia, i.e. Hauptschule (vocational preparatory school), Realschule (intermediate school), Gymnasium (grammar school) and Gesamtschule 
(comprehensive school). The sample was drawn from an inner city, an urban, and a rural area. The schools and classes were selected and then the classes within these schools. The questionnaires were distributed in the classrooms and took about 90 minutes to complete under the supervision of a member of the research team.

\section{Measurement of major variables}

I. Psychosomatic disorders were operationalized through presentation of a general symptoms checklist. Checklists of this type have the advantage that, within the framework of a survey technique, they can be competently answered by the interviewees (Wuggenig and Engel, 1986). Our checklist was based on a series of 24 symptoms, initially. The symptoms were first identified in open-ended, semi-structured discussions with 20 subjects about problematic experiences relating to different domains of their lives and their attempts to deal with them. In the thematic analysis of these discussions certain psychosomatic disorders appeared which finally led to their being included in the symptoms checklist. Our procedure closely resembles the technique used by Pearlin and Lieberman (1979).

The adolescents were asked the following questions: "How often do you suffer from the following complaints?" For each of the complaints we asked, if they occurred "frequently", "sometimes", "seldom", or "never". Ir order to get a symptom-structure analysis of the psychosomatic disorders on the basis of this operationalization, we calculated a factor analysis of the complete list of 24 symptoms. We compared the results of a maximum-likelihood factor analysis (ML) and a principal-component analysis (PC), excluding all unstable items. The final result was a reduced set of 12 symptoms. Factor I groups together those symptoms that can be defined as "vegetative syndrome", whereas factor 2 subsumes those with a more "physiological" background. On the basis of the ML-factor analysis, which explains 36 per cent of the variance, we calculated the two individual factor scores and the total score of all 2 symptoms for each adolescent. The total score is an index which counts the amount of symptoms experienced "sometimes" or "frequently".

To check the validity of adolescents' self-reports of psychosomatic disorders, we correlated the scores on the symptoms checklist with two additional variables of our study. First, with the frequency score for "specific diseases". We found that there was significant correlation between syndromes such as circulatory disorder, heart trouble, digestive trouble, allergy and asthma and the individual factor scores for psychosomatic symptoms. We take this as positive evidence of the validity of adolescents' self-reporting on health problems. Second, with the information adolescents gave on their 
Hurrelmann, K., Failure in school, family conflicts, and psychosomatic disorders in adolescence, Journal of Adolescence, 11:3 (1988:Sept.) p.237

SCHOOL, FAMILY CONFLICTS AND PSYCHOSOMATIC DISORDERS 243 consumption of medicines during the previous months. Significant correlations could be shown, for example, between the symptoms such as headache and the use of headache tablets $(r=0.45)$, sleep disturbances and sleeping pills or sedatives, or dizziness and cardiac remedies/circulatory preparations $(r=0.27)$. We believe that this result also reflects a satisfactory validity of our measure of psychosomatic disorders.

Of the items on the checklist, headaches and nervousness/restlessness were reported most frequently, i.e., symptoms which represent both of the two factors mentioned (Table 2). Female adolescents reported psychosomatic problems with significantly greater frequency than did males, so that this variable must be seen as containing a strong sex-specific element.

2. The variable "failure in school/risk of downward mobility" is registered on an index which examines for each individual and his or her previous

Table 1. Factor structure of the reduced set of psychosomatic complaints (maximumlikelihood procedure $M L$ )

\begin{tabular}{lc}
\hline Factor 1 ("vegetative syndrome") & Loadings \\
Trembling hands & $\cdot 62$ \\
Nervousness/restlessness & $\cdot 62$ \\
Lack of concentration & $\cdot 54$ \\
Palpitations & $5 \mathrm{I}$ \\
Sweating attacks & $\cdot 49$ \\
Sleeplessness/disturbed sleep & $\cdot 48$ \\
& \\
Factor 2 ("physiological syndrome") & \\
Attacks of nausea & $\cdot 63$ \\
Stomach pains & $\cdot 62$ \\
Dizziness & 53 \\
Headaches & $\cdot 50$ \\
Lack of appetite & $\cdot 40$ \\
Breathing problems & $\cdot 33$ \\
\hline
\end{tabular}

Table 2. Percentage frequency of psychosomatic disorders $(n=1717)$

\begin{tabular}{lccc}
\hline & \multicolumn{3}{c}{ Occurrence } \\
\cline { 2 - 4 } Symptoms & "Often" & "Sometimes" & "seldom/never" \\
\hline Headaches & $20 \%$ & $28 \%$ & $52 \%$ \\
Nervousness/restlessness & $16 \%$ & $25 \%$ & $59 \%$ \\
Dizziness & $12 \%$ & $18 \%$ & $70 \%$ \\
Lack of concentration & $9 \%$ & $27 \%$ & $64 \%$ \\
Stomach pains & $9 \%$ & $21 \%$ & $70 \%$ \\
Sleeplessness/disturbed sleep & $9 \%$ & $16 \%$ & $75 \%$ \\
\hline
\end{tabular}




\section{K. HURRELMANN, U. ENGEL, B. HOLLER, AND E. NORDLOHNE}

scholastic career whether or not the following condition applies: a risk of repeating a grade because of bad marks has occurred once or twice; or a school grade has actually been repeated once or twice; or a transfer of schools because of bad marks has occurred. On this index the score is I, if the condition is fulfilled, if not, it is o.

3. The variable "social conflict with parents" was constructed on the basis of a set of six indicators denoting disagreement with parents (school performance, untidiness, refusing to help with household chores, clothes/ hairstyle, smoking, wanting to go out in the evening). Subjects were asked whether there had been occasional or frequent arguments on these issues during the preceding three months ("frequently/sometimes/seldom/never"). The factor analysis of these six scales produced a two-factor structure (variance accounted for: $F_{1}: 26$ per cent, $F_{2}: 8$ per cent). The first factor is included in the present analysis via individual factor scores. This factor represents the disagreement over untidiness (factor loading $=0.7 \mathrm{I}$ ), refusing to help with household chores $(0.54)$, and school performances $(0.40)$.

4. The variable "emotional conflict with parents" is based on a set of six indicators. The interviewees were asked: "How do you feel about the situation at home?" Six responses were possible in the form of three contrasting pairs: "You are content, you feel accepted, you feel happy"/"You are not content, you feel rejected, you don't feel happy". Possible replies were: "frequently, sometimes, seldom, never". The factor analysis of these six scales produced a two-factor structure (variance accounted for: 49 per cent). The first factor is included in the present analysis via individual factor scores. This factor represents the negative statements: feeling unhappy $(0.86)$, feeling rejected $(0.50)$, feeling disconnected $(0.44)$. Female subjects reported emotional conflict significantly more often than did males.

\section{FINDINGS: PSYCHOSOMATIC DISORDERS AS MANIFESTATIONS OF STRESSFUL EXPERIENCES IN SCHOOL AND FAMILY}

First, our data provide evidence for hypothesis I, which states that the frequency of psychosomatic disorders is raised when there is a risk of downward mobility because of failure in school. Table 3, first column, gives the percentage figures for the group of students with an above- and below-average number of symptoms (for the two individual factor scores of symptoms, using the median as cut-off point), and the occurrence or non-occurrence of failure in school. The data show that in the group with failure in school the scores for an above-average frequency of psychosomatic disorders are significantly higher than in the group without failure in school. This relationship holds for both the vegetative and the physiological syndrome. Obviously, a successful scholastic biography plays an important 
role in adolescents' well-being: if the school record is not successful, it can be a source of psychosocial stress and lead to the manifestation of stress symptoms.

Second, our data support hypothesis 2 , which states that the frequency of disorders increases when social conflict with parents is intense. The data show that in the group reporting considerable conflict at home, the scores for an above-average frequency of disorders are higher than in the group with low conflicts. This result corroborates the tenability of hypothesis 2 .

Third, our data confirm hypothesis 3 , which states that the frequency of psychosomatic disorders is higher when there is emotional conflict in the family. The data show that in the group reporting intense emotional conflict the above-average number of symptoms of disorders is higher than in the group with little emotional conflict. This result substantiates the tenability of hypothesis 3 .

Table 3. Percentage distribution of psychosomatic disorders with failure in school and social conflicts and emotional conflicts with the parents

\begin{tabular}{lcc}
\hline & \multicolumn{2}{c}{$\begin{array}{c}\text { Frequency of above-average } \\
\text { psychosomatic symptoms for }\end{array}$} \\
\cline { 2 - 3 } Experience ... & $\begin{array}{c}\text { Factor } \text { I }^{*} \\
\text { (vegetative } \\
\text { syndrome) }\end{array}$ & $\begin{array}{c}\text { Factor 2* } \\
\text { (physiological } \\
\text { syndrome) }\end{array}$ \\
\hline Failure in school & $56 \%$ & $54 \%$ \\
No failure in school & $46 \%$ & $48 \%$ \\
High level of social conflicts & $59 \%$ & $58 \%$ \\
Low level of social conflicts & $41 \%$ & $4 \mathrm{I} \%$ \\
High level of emotional conflicts & $62 \%$ & $60 \%$ \\
Low level of emotional conflicts & $4 \mathrm{I} \%$ & $4 \mathrm{I} \%$ \\
\hline
\end{tabular}

$P=<0.05$ for all distributions.

* Based on the individual factor scores, using the median as cut-off point.

A comparison of the findings presented in Table 3 reveals that the correlations with "frequency of psychosomatic disorders" are strongest for the variable "emotional conflicts". An interesting aspect is that the manifestations of the vegetative syndrome (trembling hands, nervousness, lack of concentration, palpitations etc.) are consistently more marked than those of the physiological syndrome (nausea, stomach pains, dizziness etc.).

The empirical findings are so far based on bivariate analyses only, a fact which could be potentially misleading since it involves a high risk of spurious correlations. Therefore, the tenability of the hypotheses should additionally 
Hurrelmann, K., Failure in school, family conflicts, and psychosomatic disorders in adolescence, Journal of Adolescence, 11:3 (1988:Sept.) p.237
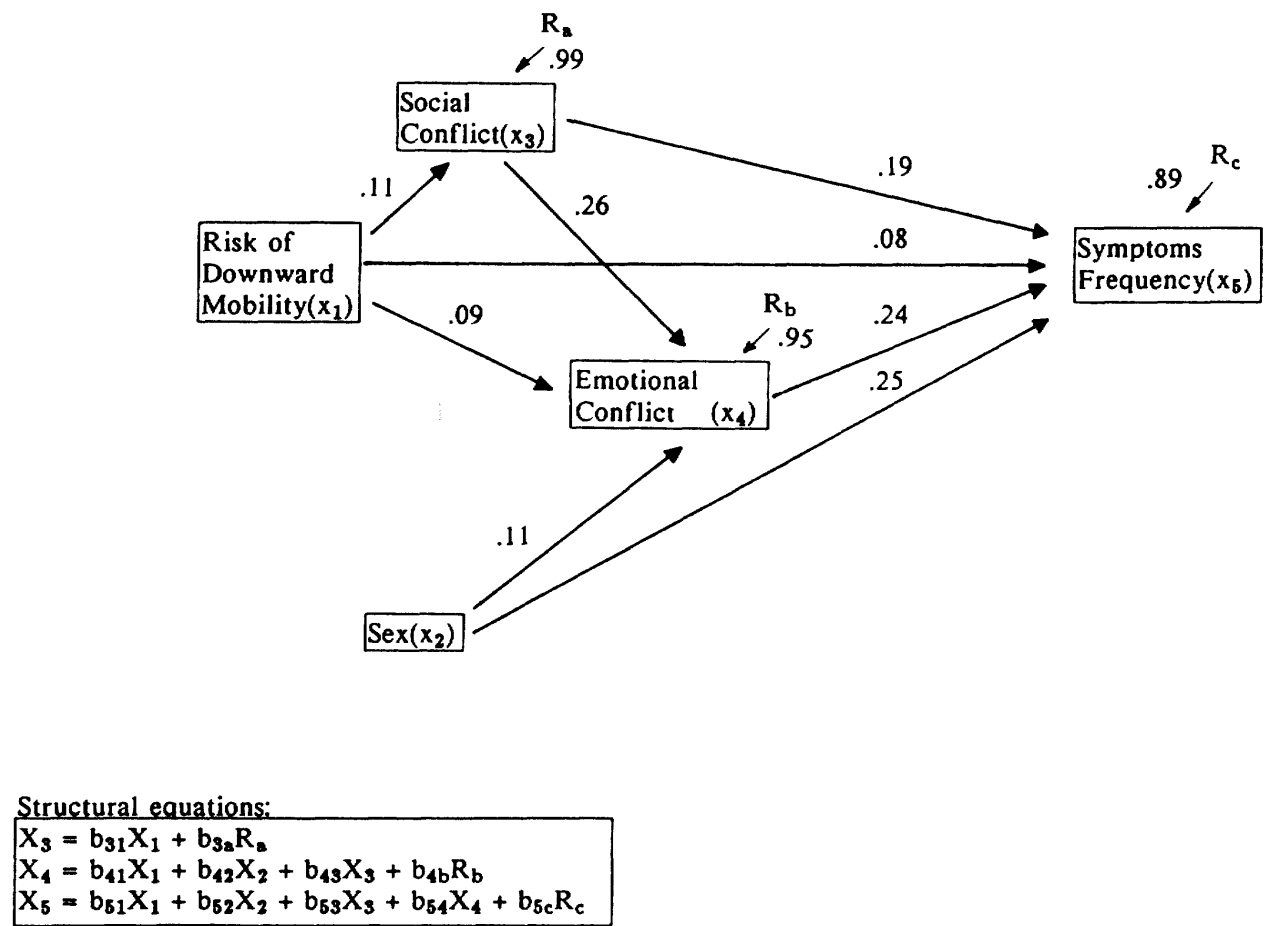

all b's standardized path coefficients

Figure 1. The complete path model, including the standardized path coefficients of the structural equations; equations are also given.

be assessed on the basis of the common multivariate frequency distribution of the variables involved. Also, the intercorrelations between the three variables of school failure, social conflicts with parents, and emotional conflicts with parents should be explicitly taken into account in order to check whether both social and emotional conflicts at home are aggrevated when there is a risk of educational downward mobility, and to find out whether social conflicts at home intensify emotional conflicts with parents.

A suitable method to consider simultaneously the correlations of all variables mentioned within the framework of a combined model is by way of path analysis. To arrive at unconfounded estimates of effect, the variable "sex of subjects" has additionally to be included in the path analysis model, because we know from bivariate analysis that both emotional conflicts and psychosomatic disorders are sex-related functions: On the average girls report more symptoms and experience emotional conflicts at home more often than boys. 
Figure I illustrates that the symptoms frequency increases directly and indirectly due to failure in school and the risk of downward mobility. Apart from the direct effect, one path runs via social conflict and the other via emotional conflict with the parents. Both paths provide important partial explanations which permit the conclusion that failure in school, and thus the risk of downward mobility, reinforces the psychosomatic symptoms for the reason that (in addition to other determinants) it causes social conflict and/or emotional conflict at home which in turn increases the frequency of symptoms.

The model shows that, in methodological terms, social and emotional conflict do not constitute intervening variables in a full sense, for the variable "risk of downward mobility" retains a direct influence on the frequency of symptoms. Moreover, the model suggests that emotional conflict may also be interpreted as a result of social conflict at home: One reason why social conflict reinforces the psychosomatic symptoms is that it causes emotional conflict which, in turn, affect the frequency of psychosomatic disorders. As the corresponding path coefficients show, through emotional conflict the variable "sex of subjects" also has a direct as well as an indirect influence on the symptoms frequency of psychosomatic disorders.

The findings presented in Figure I turn out to be fully replicable when the variable $\times_{5}$ of the structural equations model, which, for each individual, measures the frequency of all symptoms, is replaced by the individual-factorscores variables.

\section{SUMMARY AND DISCUSSION}

Our data show that the risk of failure in school and its actual occurrence constitute a source of psychosocial stress in adolescence. Students exposed to the risk of having to repeat a grade or to transfer to a lower type of school due to poor performance and, as a consequence, the risk of not attaining a school-leaving certificate in line with their parents' and their own aspirations and plans, undergo a highly stressful experience. Obviously the risk of occupational and social downward mobility in the future is responsible for the "costs" manifested in a high percentage of an above-average number of health problems, such as the psychosomatic disorders discussed above.

Our data are the result of a survey study undertaken in West Germany. Thus, they mirror the specific educational and occupational opportunity structures encountered in this country. As has been pointed out, the threat of downward social mobility is of great concern to West German adolescents because the spiralling effect of the level of school-leaving certificates makes it difficult for adolescents to fulfill the preconceived status expectations of their parents. 
In view of the interconnections between educational failure, on the one hand, and conflict and tension with parents, on the other, that we found in our analysis, we can show that this interrelatedness of the educational and the familial context has a demonstrable effect on the process of status transition in adolescence. Obviously, psychosomatic disorders (as manifestations of social stress) are likely to increase if there is a combination of unfavourable conditions affecting major spheres of adolescent life. Our findings thus highlight the crucial and pervasive effect of school during adolescence in that the foundations for future occupational and social status are laid during this period: the position reached on the ladder of academic attainment functions as a starting point and trigger for adolescents' well-being even outside the school environment and particularly at home.

During adolescence it is especially the family which plays an important role in influencing occupational choices. Parents' assessment of academic achievement in relation to its career impact is one of their major functions. Our study shows that the social and emotional climate of family relationships is adversely affected by poor school performance; at the same time, the atmosphere at home is a mediating factor vis-à-vis problems which may result from school failure. Our conclusion is that against the background of increased competition in the labour market in recent years, the interconnections between school-failure and the quality of family relations revealed here have become progressively more significant, and will continue to do so, thus constituting a source of considerable tension which might interfere with satisfactory relations between adolescents and parents. Clearly, the underlying causes for the tensions are to be found outside the family in the social and economic opportunity structures of society.

\section{REFERENCES}

Boudon, R. (1974). Education, Opportunity, and Social Inequality. New York: Wiley.

Bourdieu, R. (1984). Distinction: A Social Critique of the Fudgement of Taste. London: Routledge \& Kegan Paul.

Bundesminister für Bildung und Wissenschaft (1986). Grund-und Strukturdaten. Bad Honnef: Bock.

Collins, R. (1979). The Credential Society. New York: Academic Press.

DiMaggio, P. (I982). Cultural capital and school success: the impact of status culture participation on the grades of U.S. High School students. American Sociology Review 47, 189-201.

Coleman, J. C. (1980). The Nature of Adolescence. New York: Basic Bocks.

Engel, U. (1987). Youth, mobility and social integration. In Youth Research in Westerm Germany, Hazekamp, O. (Ed). Amsterdam: Free University Press.

Entwisle, D. and Hayduk, L. A. (1981). Academic expectations and the school attainment of young children. Sociology of Education 54, 34-50.

Hamburg, B. A. (r980). Early adolescence as a life stress. In Coping and Health, Levin, S. and Ursin, H. (Eds) New York: Plenum Press, pp. I2I-I43. 
Hurrelmann, K., Failure in school, family conflicts, and psychosomatic disorders in adolescence, Journal of Adolescence, 11:3 (1988:Sept.) p.237

\section{SCHOOL, FAMILY CONFLICTS AND PSYCHOSOMATIC DISORDERS 249}

Hotaling, G. T., Atwell, S. G. and Linsky, A. S. (1978). Adolescent life changes and illness. Fournal of Youth and Adolescence 7, 393-402.

Hurrelmann, K. (1984a). Adjusting to an erosion of opportunities: the experience of West German youth. Policy Studies 5, 43-65.

Hurrelmann, K. $(1984 b)$ : Societal and organizational factors of stress on students in school. European fournal of Teacher Education 7, 181-190.

Hurrelmann, K. ( 1987$)$ : The limits and potential of social intervention in adolescence. In Social Intervention: Potential and Constraints, Hurrelmann, K., Kaufmann, F. X., and Lösel, F. (Eds). Berlin/New York: De Gruyter, pp. 219-240.

Jessor, R. and Jessor, S. L. (1977). Problem Behavior and Psychosocial Development. A Longitudinal Study of Youth. New York: Academic Press.

Johnson, J. H. (1986). Life Events as Stressors in Childhood and Adolescence. Newbury Park: Sage.

Moriarty, A. E. and Toussieng, M. D. (1976). Adolescent Coping New York: Grune \& Stratton.

Murphy, L. B. and Moriarty, A. E. (1976): Vulnerability, Coping and Growth from Infancy to Adolescence. New Haven: Yale University Press.

Newcomb, N. D., Huba, G. J. and Bentler, P. M. (I98I): A multidimensional assessment of stressful life events among adolescents. Fournal of Health and Social Behavior 22, 400-4I 5 .

Pearlin, L. I. and Lieberman, M. A. (1979). Social sources of emotional distress. In Research in Community and Mental Health, Simmons, R. (Ed.). Greenwich: JAI-Press, pp. 214-248.

Pearlin, L. I. ( 1987 ). The stress process and strategies of intervention. In Social Intervention: Potential and Constraints, Hurrelmann, K., Kaufmann, F.-X. and Lösel, F. (Eds.). Berlin/New York: De Gruyter, pp. 53-72.

Persell, C. H. (1977). Education and Inequality. New York: The Free Press.

Petersen, A. C. and Craighead, W. E. (1986). Emotional and personality development in normal adolescents and young adults. In Suicide and Depression Among Adolescents and Young Adults, Leiman, G. L. (Ed.). Washington: APP Press, pp. 19-52.

Rutter, M. (1980). Changing Youth in a Changing Society. Cambridge: Harvard University Press.

Siddique, C. M., and D'Arcey, C. (1984): Adolescence, stress, and psychological well-being. Foumal of Youth and Adolescence 113, 459-473.

Silbereisen, R., Eyferth, K. and Rudinger, G. (Eds) (1986). Development as Action in Context. New York: Springer.

Wuggenig, U. and Engel, U. (1986): Statusinkonsistenz, mentale Inkongruenz und Stress: Ergebnisse der vergleichenden Theorientestung. Hannover: University of Hannover Press. 